\title{
Comparison of mechanical performance between friction-stir spot welded and adhesive bonded joints
}

\author{
A. M. Amaro \\ University of Coimbra, CEMMPRE, Dep. of Mechanical Engineering, Portugal. \\ ana.amaro@dem.uc.pt, bttp:// orcid.org/0000-0001-5237-0773
}

\author{
A. Loureiro \\ University of Coimbra, CEMMPRE, Dep. of Mechanical Engineering, Portugal. \\ altino.loureiro@dem.uc.pt bttp://orcid.org/0000-0001-9315-3177
}

P.N.B. Reis

C-MAST, Dep. of Electromechanical Engineering, University of Beira Interior, Covilhã, Portugal preis@ubi.pt bttp:/ / orcid.org/0000-0001-5203-3670

\begin{abstract}
The main goal of this study is to compare the morphology and mechanical strength of friction stir spot welded (FSSW) joints and adhesive bonded stepped joints. The welded joints were produced by friction stir spot welding, while the adhesive bonded ones used an Araldite 420 A/B adhesive. All joints were subjected to morphology and microstructure analyses, microhardness tests, tensile-shear tests and local strain analyses. It was possible to conclude that the welded joints have higher strength than adhesive-bonded joints. However, this difference is insignificant, around $5 \%$, which is covered by the standard deviation. Therefore, FSSW technique proves to be an alternative to adhesive bonded joints, offering the same strength. Nevertheless, the friction stir spot welded induces isolated connection points, which are responsible for stress concentrations.
\end{abstract}

KEYwORDS. Adhesive bonding; Friction-stir welding; Aluminium adherends.

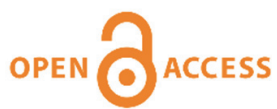

Citation: Amaro, A. M., Loureiro, A., Reis, P.N.B., Comparison of mechanical performance between friction-stir spot welded and adhesive bonded joints, Frattura ed Integrità Strutturale, 53 (2020) 124-133.

Received: 10.02 .2020

Accepted: 08.05.2020

Published: 01.07.2020

Copyright: (C) 2019 This is an open access article under the terms of the CC-BY 4.0, which permits unrestricted use, distribution, and reproduction in any medium, provided the original author and source are credited.

\section{INTRODUCTION}

$\mathrm{F}$ riction stir welding (FSW) was invented in 1991 at The Welding Institute (TWI) of UK and, it is considerate to be the most significant development in the joining technology due to its energy efficiency, environment friendliness and versatility. Literature even considers this solid-state joining technique as a "green" process, because of no aggressive radiation emission and no cover gas or flux is used, beyond the lowest energy required when compared to the traditional ones. On the other hand, in terms of economic aspects, this technique drastically reduces the weld preparation costs, skilled welder requirements and repair rates [1]. Mishra and Ma [2], for example, report the benefits obtained with the friction stir welding. Basically, due to the lower temperatures involved, many materials are capable of being joined with good mechanical properties, low distortions, good surface finish, and high automation potential [3]. 
Nowadays, it is well known that FSW has quickly gained acceptance as an efficient method of joining in the maritime, aerospace, automotive and rail sectors [1]. For example, the Eclipse 500 business jet was the first aircraft that completed the certification of FSW in detriment of the fasteners [1, 4]. In this aircraft around 7300 fasteners (approximately $60 \%$ of the total) were replaced by 263 friction stir welds. In terms of automotive sector, Mazda Rx-8 sports car use FSW on the aluminium bonnet and rear doors $[1,4]$. However, in these industries adhesive joints are a promising and alternative technique because they promote several advantages like smaller stress concentration, absence of fretting between materials to be joined, improved fatigue behavior and easier conformance to complex shapes, amongst many other factors [5]. All these advantages become more relevant every day with the development of more feasible and durable adhesives [6].

Associated to the adhesive joints is the single lap geometry, because it presents the simplest joint shape. However, due to the loading eccentricity, the joint's rotation promote peel and shear stresses with maximum values near to the extremities of the joint and close of the adhesive/adherends interface [7]. These peak values move into the interior of the joint for higher loads, and according to Sancaktar and Nirantar [8] the maximum stresses at the overlap edges are determinants on the failure of such joints. Therefore, literature reports that is possible to improve the final strength of single lap joints by changing the adherends and adhesive strength $[9,10]$ as well as the elastic modulus of the adhesive [11,12] and/or adherend $[13,14]$, adherend and adhesive thickness $[15,16]$, overlap length $[17,18]$ and fillets at the overlap edges $[19,20]$. In the last case, for example, literature even suggests geometries with modified edges in terms of adhesive [21], adherend [22, 23] or both $[24,25]$. Finally, compact solutions of the corner singularity in an adhesively bonded joint were, inclusively, proposed by Wang and Rose [26].

Keeping the same configuration, but in an attempt to decrease the stress concentration, stepped joints have been found to exhibit the highest structural efficiency because significant joint load path eccentricities are eliminated when compared with simple single lap joints [27]. In fact, the stepped lap joint can be considered as a joint to have many single lap joints which end is bonded with adhesive [28]. However, independently of the success achieved with the stepped lap joints, damage tolerance principles suggest hybrid joining technologies, in which two or more different joining techniques are combined to ensure more stringent safety criteria. In such contexts, it is necessary to have a detailed knowledge of each one for a future hybridization. Therefore, the stepped joint will be used to compare the mechanical performance of friction stir spot welds against adhesive joints, because, according to the authors' knowledge, this study is not yet reported in the literature. For this purpose, the considered stepped lap joint includes only three steps and the mechanical strength was compared with resource to static tensile tests.

\section{MATERIALS AND EXPERIMENTAL PROCEDURE}

1 his study involves a series of adhesive single lap joints (SLJ) using adherends from an AA5083- H111 aluminium alloy plate, of $120 \times 120 \times 3 \mathrm{~mm}$ size, and an epoxy adhesive Araldite ${ }^{\circledR} 420 \mathrm{~A} / \mathrm{B}$. This adhesive has very high strength and toughness and, according to the open literature [3], when combined in FSW+AB joints it reaches a strength level similar to the adhesive joints. The nominal mechanical properties and chemical composition of the adherends and are provided in Tables 1 and 2, respectively. The mechanical properties of the adhesive are in Table 3. The geometry and dimensions of the specimens are shown in Figure 1. The weld was made in the same position that the adhesive, but in only one spot. For all configurations, alignment tabs were used in order to reduce the singularity of the load and, consequently, high peel stress in the adhesive.

\begin{tabular}{cc}
\hline Alloy & AA5083 - H111 \\
Tensile Strength & $270-345 \mathrm{MPa}$ \\
Proof Stress & $115 \mathrm{MPa}$ Min \\
Hardness (Brinell) & $75 \mathrm{HB}$ \\
Elongation A & $12 \% \mathrm{Min}$ \\
\hline
\end{tabular}

Table 1: Mechanical properties of the adherends [29].

\begin{tabular}{cccccccccc}
\hline Alloy & Si & Fe & Mg & Mn & Cr & Zn & Ti & Al \\
AA5083-H111 [\%] & $\leq 0.40$ & $\leq 0.40$ & $4-4.9$ & $0.4-1.0$ & $0.05-0.25$ & $\leq 0.25$ & $\leq 0.15$ & Balance \\
\hline
\end{tabular}

Table 2: Chemical composition of the adherends wt. (\%) [30]. 


\begin{tabular}{cccccc}
\hline Adhesive & $\sigma_{\text {uts }}[\mathrm{MPa}]$ & $\sigma_{\mathrm{YS}}[\mathrm{MPa}]$ Strain $0.2 \%$ & Young's Modulus, E [GPa] & $\varepsilon_{\mathrm{f}}[\%]$ & $v$ \\
Araldite $^{\circledR} 420 \mathrm{~A} / \mathrm{B}$ & 35 & 27 & 1.85 & 8.5 & 0.3 \\
\hline
\end{tabular}

Table 3: Mechanical properties of the adhesive [31].

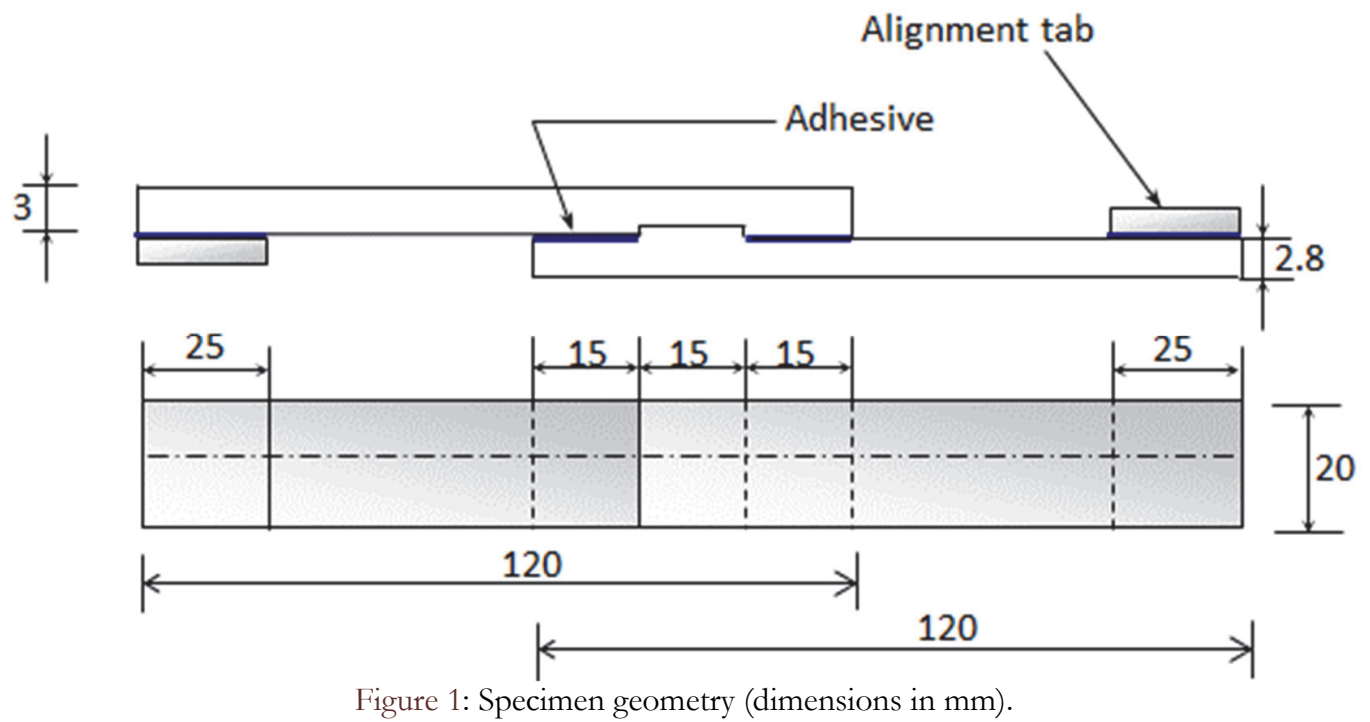

The samples were split in two groups: adhesive joints and FSSW joints. Relative to the adhesive joints, and before bonding, some superficial oxides were removed from the surfaces to bond with 220-mesh water sandpaper and cleaned with acetone to remove any contaminants. After bonding, the adhesive was cured at $50^{\circ} \mathrm{C}$ for $4 \mathrm{~h}$ in a muffle PJ Selecta Model Digithead. In order to ensure a constant bondline thickness, the specimens were compressed with a constant pressure of about 0.12 $\mathrm{MPa}$, uniformly applied by a weight loading system for specified curing time. This pressure value was selected according to previous works $[32,33]$, and an optical microscope with a micrometric base was used to measure the bondline thickness. An average value of $0.11 \mathrm{~mm}$ was obtained without significant dispersion (standard deviation (SD) of $0.009 \mathrm{~mm}$ ). In terms of the FSSW joints the tool used has a shoulder diameter of $14 \mathrm{~mm}$ and a conical pin of $6 \mathrm{~mm}$ diameter in the base and 3 $\mathrm{mm}$ in the tip and a height of $2.7 \mathrm{~mm}$. The tool rotational speed was of $500 \mathrm{rpm}$ and the tool plunge depth of $3.1 \mathrm{~mm}$. These parameters were chosen based on previous experiments. Two strings of six equally spaced spots were placed on each pair of plates, as shown in Fig. 2 a). The welds were placed in the same places of the adhesive bonded areas. These welds were carried out in a Cincinnati Milacron machine, Model 207MK.

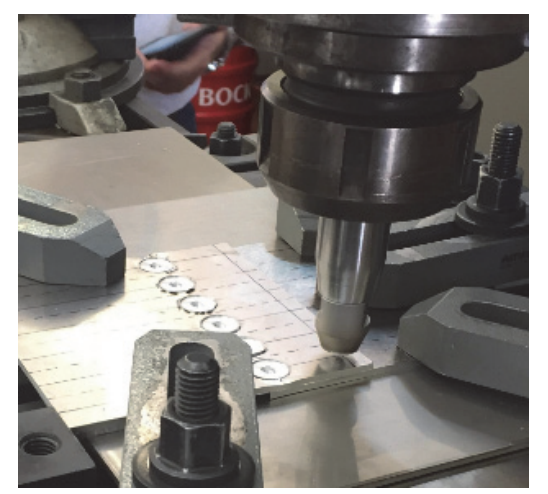

(a)

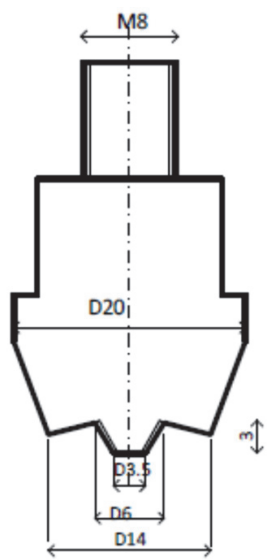

Figure 2: a) General view; b) Tool. 
A universal tensile testing machine, Instron - Model 4206, was used to carry out tensile/shear tests according to the standard ASTM D 1002-01. At least five tests were performed at room temperature in each condition, using a cross-head speed of 1 $\mathrm{mm} / \mathrm{min}$. The global strain data for the specimens were evaluated by means of an Instron $50 \mathrm{~mm}$ gauge length clip-on extensometer, Model Ex2630-112. Local strain data acquisition was achieved using an Aramis 3D 5M optical system (GOM $\mathrm{GmbH}$ ) with Digital Image Correlation (DIC) [34]. The full-field displacements of the overlap region were assessed with this system. Before the tests, all the specimens were prepared by applying a random black speckle pattern over the previously painted mat white surface of the samples before testing, in order to enable displacement data acquisition.

After the tensile/shear tests a metallographic analysis were performed. For this purpose, the specimens were obtained from the bonded and FSSW plates, mounted in epoxy resin and ground with silicon carbide papers with a particle size ranging from P600 to P2500. As it is necessary to a correct analysis the final polishing was done with a diamond suspension of 3 $\mu \mathrm{m}$ particle size and the samples were etched with Keller's reagent $(50 \mathrm{ml} \mathrm{H} 2 \mathrm{O}, 1 \mathrm{ml} \mathrm{HNO}, 2 \mathrm{ml} \mathrm{HCl}, 2 \mathrm{ml} \mathrm{HF})$ for 10 sec and analyzed with an optical microscope, Leica DM 4000 M LED. Hardness measurements were also performed using the equipment SHIMADZU HMV-G, with a load of $1.96 \mathrm{~N}$, for 15 seconds, and 80 indentations were made. The spacing between each indentation used was $1 \mathrm{~mm}$ away from the welding zone, and $0.5 \mathrm{~mm}$ close to the welding zone. Only the welding specimens were analyzed, because the bonded specimens do not show any changes in hardness compared to the base material.

\section{RESULTS AND DISCUSSION}

1 ab. 4 shows the average results (average of five specimens) obtained by the tensile/shear tests for each series, bonded and FSSW. No significant difference in the maximum load, about $5 \%$, is achieved. However, in terms of displacement this difference is about $29 \%$. Regarding Figure 3 a, it is possible to observe that the failure in bonded joints occurs essentially by adhesion, while in the welded joints (Figure 3b) the plastic deformation of adherents is visible, before the final break. According to Sun et al. [35] one of the disadvantages of spot FSW technique is the presence of a keyhole generally at the center of the stir zone, which is observed in Figure 3b. Therefore, the main limitation of the keyhole is the possibility of corrosion appearance, but the mechanical properties may be unaffected. So, both joints have advantages and disadvantages. For example, according to [36] adhesive-bonded joints guarantee a homogeneous stress distribution and, thus, absence of stress concentrations within the adhesives, but are sensitivity to temperature and aging, which can affect its use. In case of welded joints by FSSW materials are joined below melting point temperatures, which is an advantage of enabling the joining of previously difficult to weld materials with good mechanical properties and low distortions but inducing local stress concentration.

\begin{tabular}{lcccc}
\hline \multirow{2}{*}{ Joint } & \multicolumn{2}{c}{ Failure Load } & \multicolumn{2}{c}{ Displacement at Failure } \\
& Average $[\mathrm{N}]$ & Std. $[\mathrm{N}]$ & Average $[\mathrm{mm}]$ & Std. $[\mathrm{mm}]$ \\
Bonded & 5994 & 535 & 1.47 & 0.08 \\
Welded & 6301 & 638 & 2.07 & 0.11 \\
\hline
\end{tabular}

Table 4: Average values of the two different joints.

The tensile-shear behavior of the welded joints depends on the welding morphology. So, the microstructure of the base material and the morphology of the welded joints was evaluated. In the case of the bonded specimens the microstructure is the same as the base material. Figure 4 shows the microstructure observed for the base material, and Figure 5 the macrographs for the welded joints.

As observed in Figure 4 the microstructure of material base consists of grains with very irregular geometry, with an average dimension of approximately $18 \mu \mathrm{m}$, which is in accordance with other results obtained in the same material [37]. In terms of welded joints, Figure 5a shows three different zones, the nugget $(\mathrm{N})$, the thermomechanically affected zone (TMAZ) and the thermally affected zone (TAZ), as well as the final hole of the tool. These zones are shown in more detail in Figure 5b and are in accordance with the results obtained by Rodriguez et al. [38]. The nugget is the region of equiaxed grain with the smallest size $(5 \mu \mathrm{m})$, Figure $5 \mathrm{c}$. It is the region where the grains are submitted to large plastic deformation and the highest temperature is reached during the welding process, due to the frictional energy coming from the contact of the tool with the joint material. Consequently, the grains recrystallize but do not have time to grow, obtaining a refined and equiaxial 
structure [39]. The plastic deformation promoted by the tool in the TMAZ, zone which is also affected by the thermal gradients generated, induces the grain elongation, see Figure 5d. In this study the tool penetrates only the upper plate, so the most common metallurgical defects like hooking, partial bonding and bonding ligament [40] are reduced.

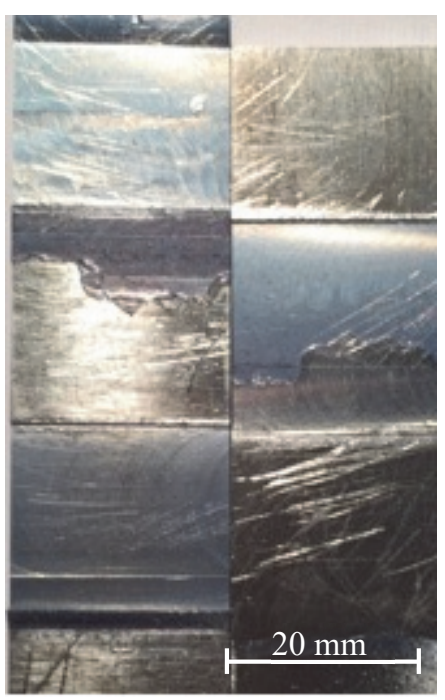

(a)

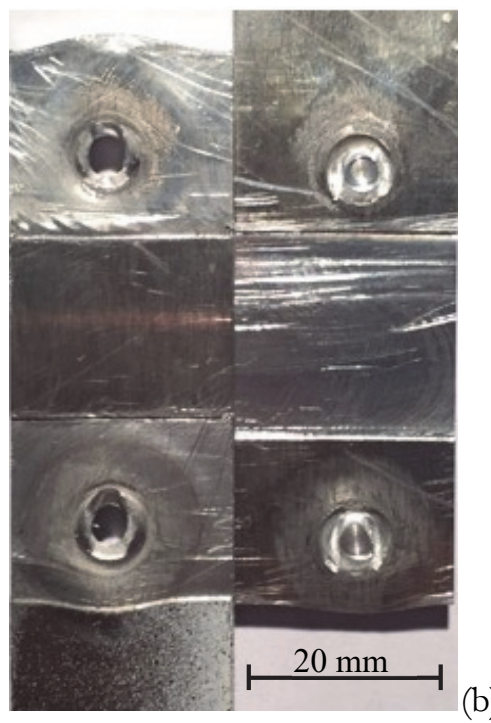

Figure 3: Breaking surfaces: a) Bonded; b) Welded.

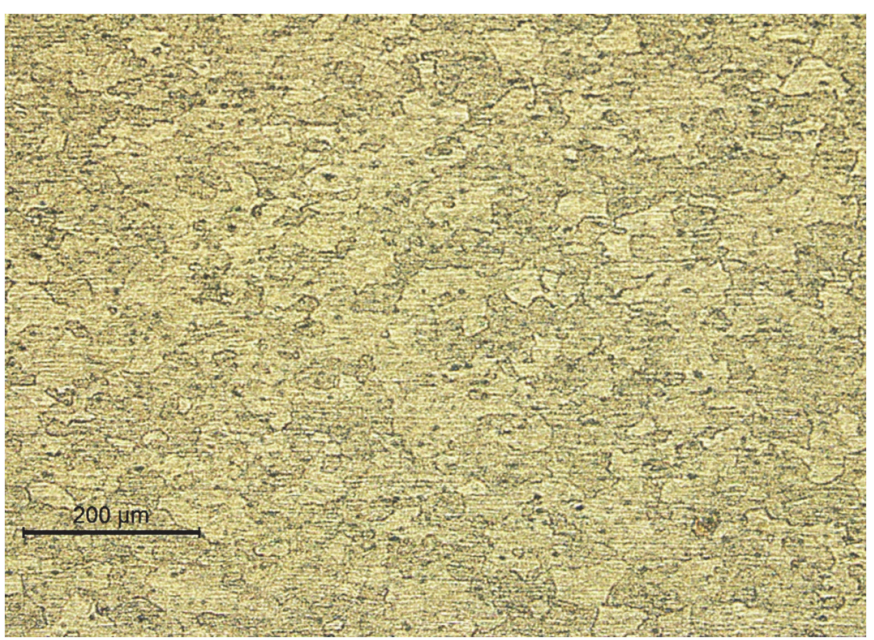

Figure 4: Microstructure of the base material.

The mechanical behavior of the adherents can be influenced by the welding, principally in the vicinity of the welds. Figure 6 illustrates the hardness profile in a plane that crosses one weld completely and the other partially, measured at half thickness of both plates. Consequently, it is possible to observe two welded zones, identified as 1 and 2. The horizontal line (grey) represents the hardness of base material, the aluminum alloy AA5083-H111.

In both welds there is an increase in hardness in the vicinity of the weld, which can be justified due to the areas near to the welding center correspond to zones that suffer greater plastic deformation, resulting from the contact of the FSSW tool with the sample. It can be also observed a decrease in the hardness at the TAZ, caused by the annealing effect [41]. It is also verified that the hardness values in weld series 2 are lower than in weld series 1 , because the plates suffer some heating due to the first series of welds. It is found that there is no hardness recovery in the upper right-hand plate, which can be justified because the heat loss on the right side of this plate, corresponding to its end, occurs only by convection, as represented schematically in Figure 7. 

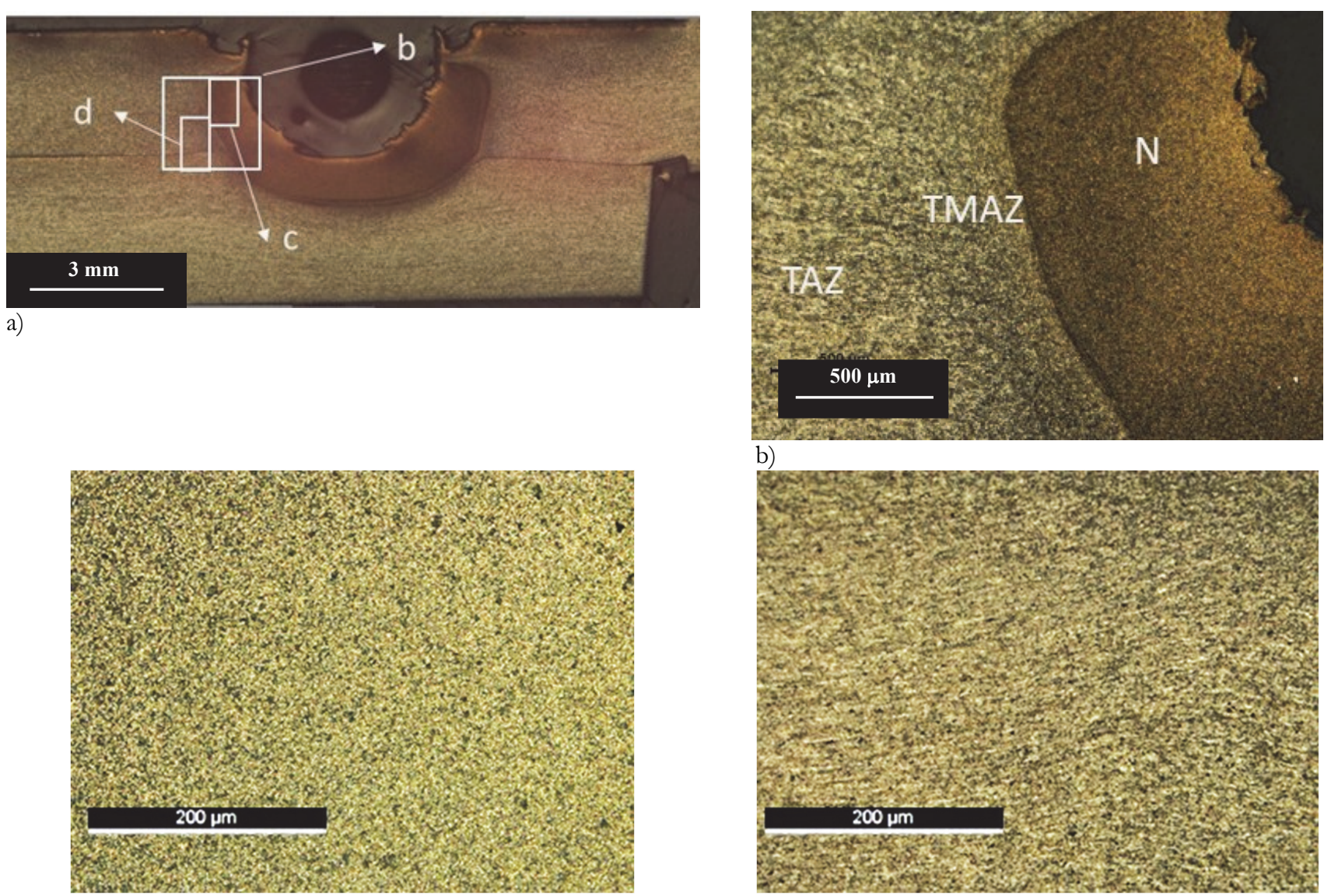

c)

d)

Figure 5: (a) Macrographs of welded joint; (b) Weld zone; (c) Nugget; (d) TMAZ.
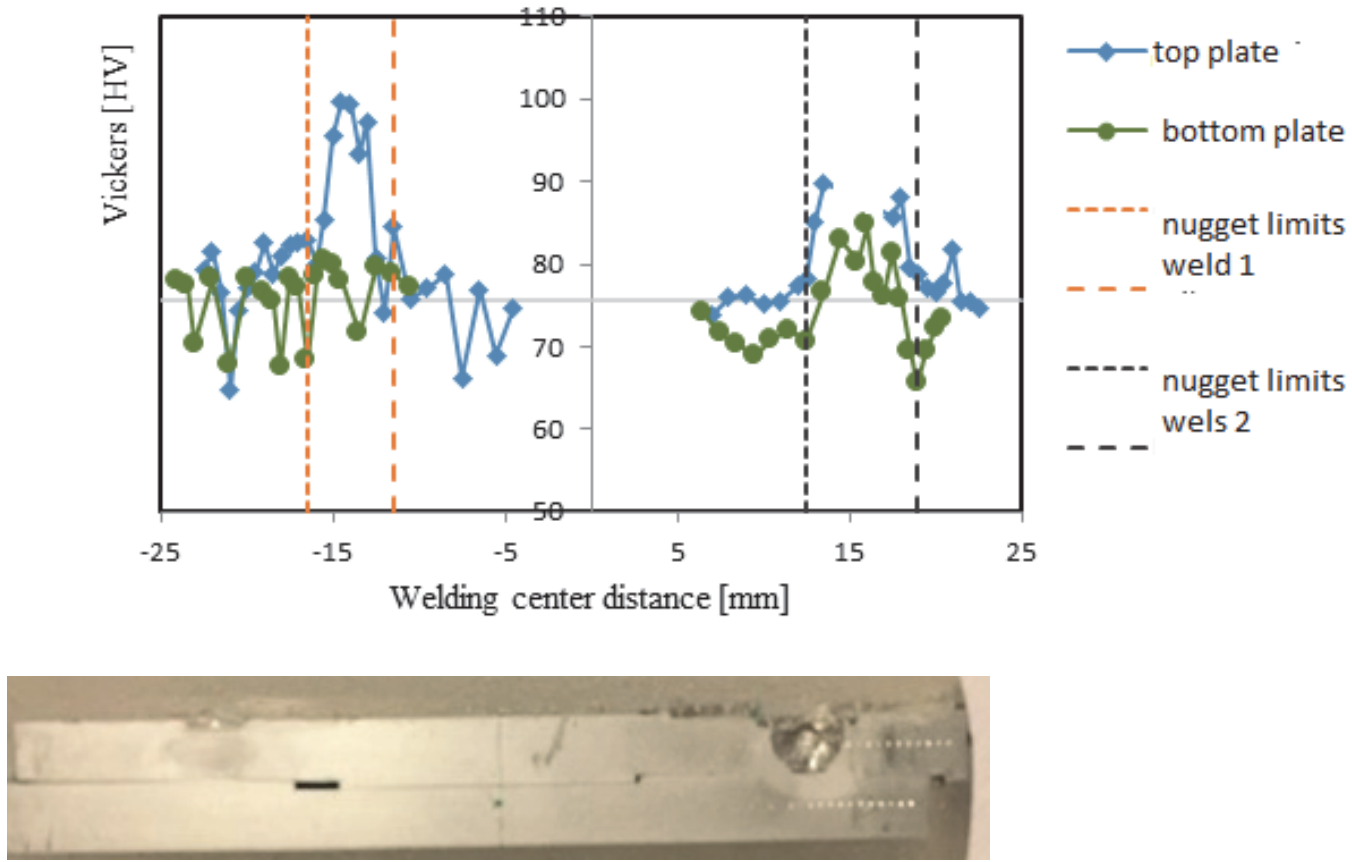

Figure 6: Hardness profile of welded joints. 


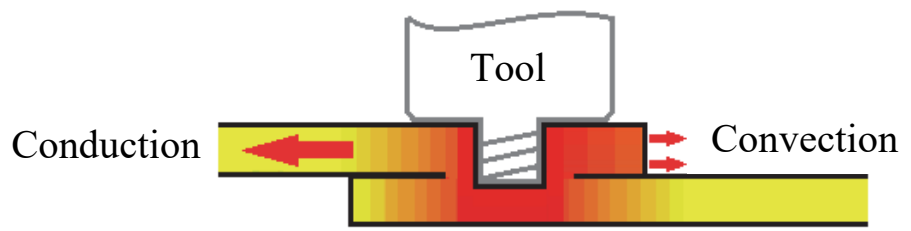

Figure 7: Schematic representation of heat dissipation from the overlapping joint's top plate.

The local strains along the thickness during tensile shear testing was evaluated using an optical extensometer with digital image correlation. The results for a adhesive bonded joint are present in Figure 8, while in the case of a welded joint in Figure 9. From Figure 8a, it may be observed that the deformation starts at the end of the overlapping zone. At the maximum load signs of moderate cleavage and pullout are shown, see Figure 8b. These phenomena are the result of some flexion of the specimen during the tensile/shear tests, which translates into tensile stresses located at the joint ends [42]. In the case of the welded joint, the joint started opening at one end of the overlapping zone, and it occurs relatively early. In fact, observing the deformation caused at middle load, the plates are already separated. Again, moderate pullout and cleavage were observed. In both cases it can be detected a small flexion of the plates, which leads to the appearance of pull-out loads at the joint.

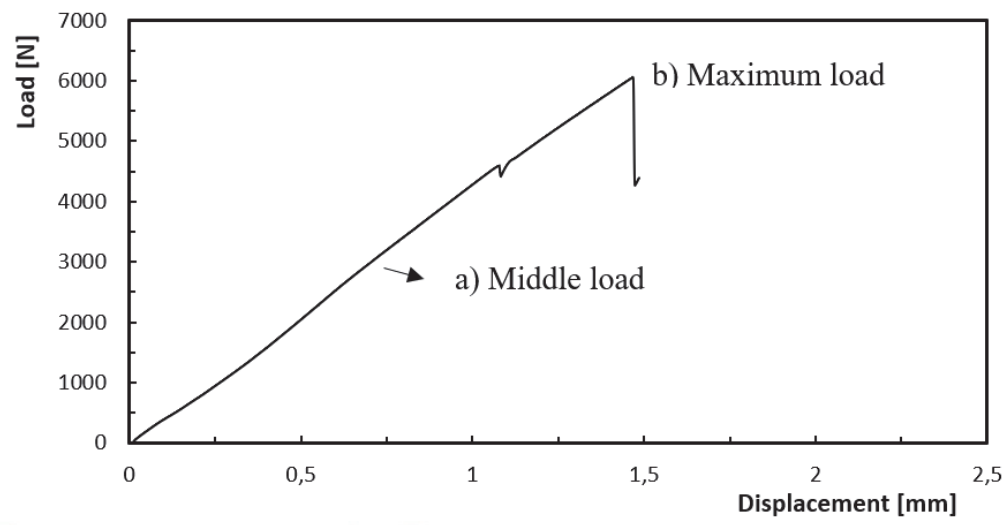

a)
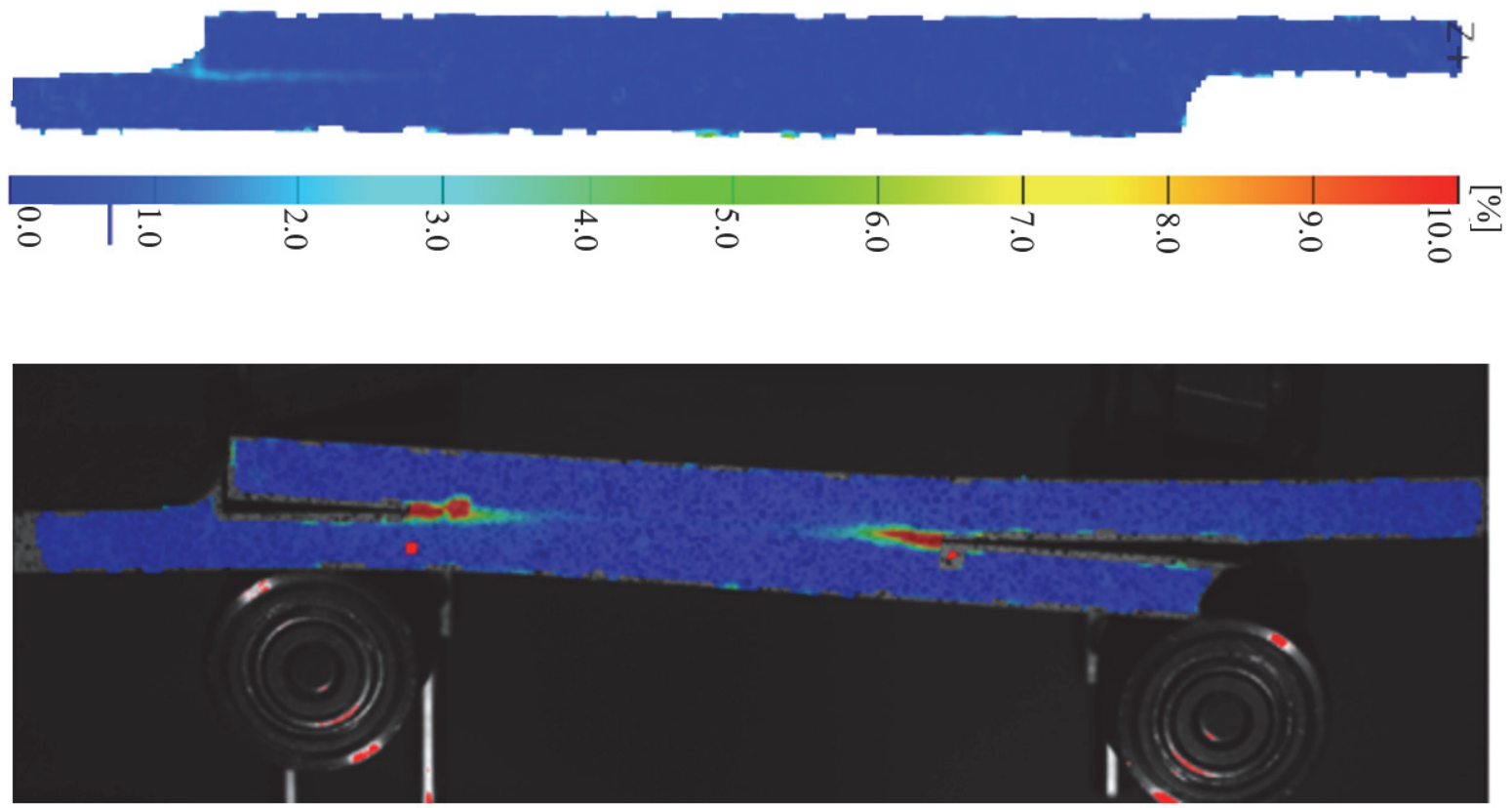

b)

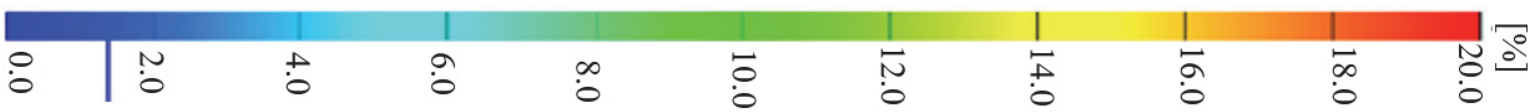

Figure 8: Local deformations on the surface of an adhesive bonded specimen at: a) middle load stage; b) maximum load stage. 


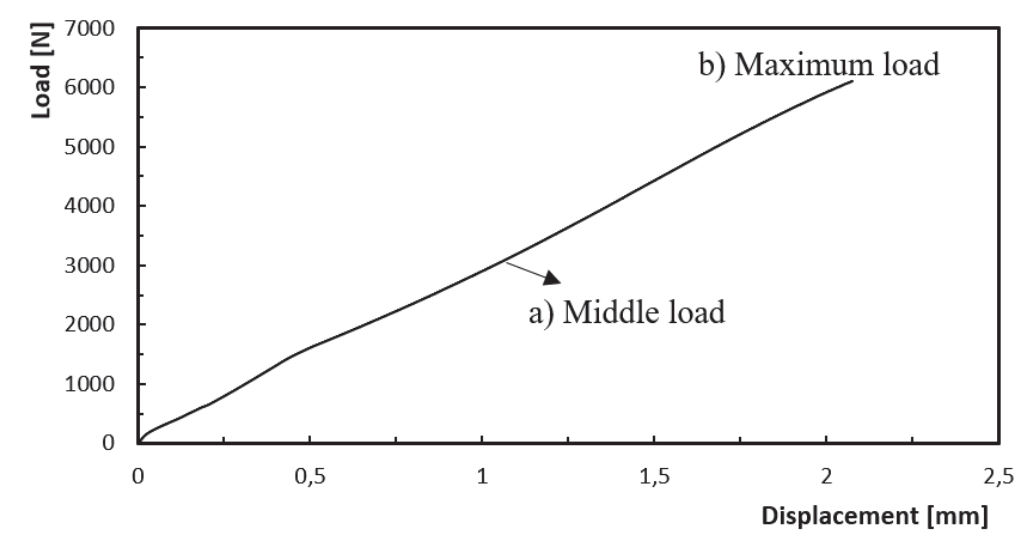

a)
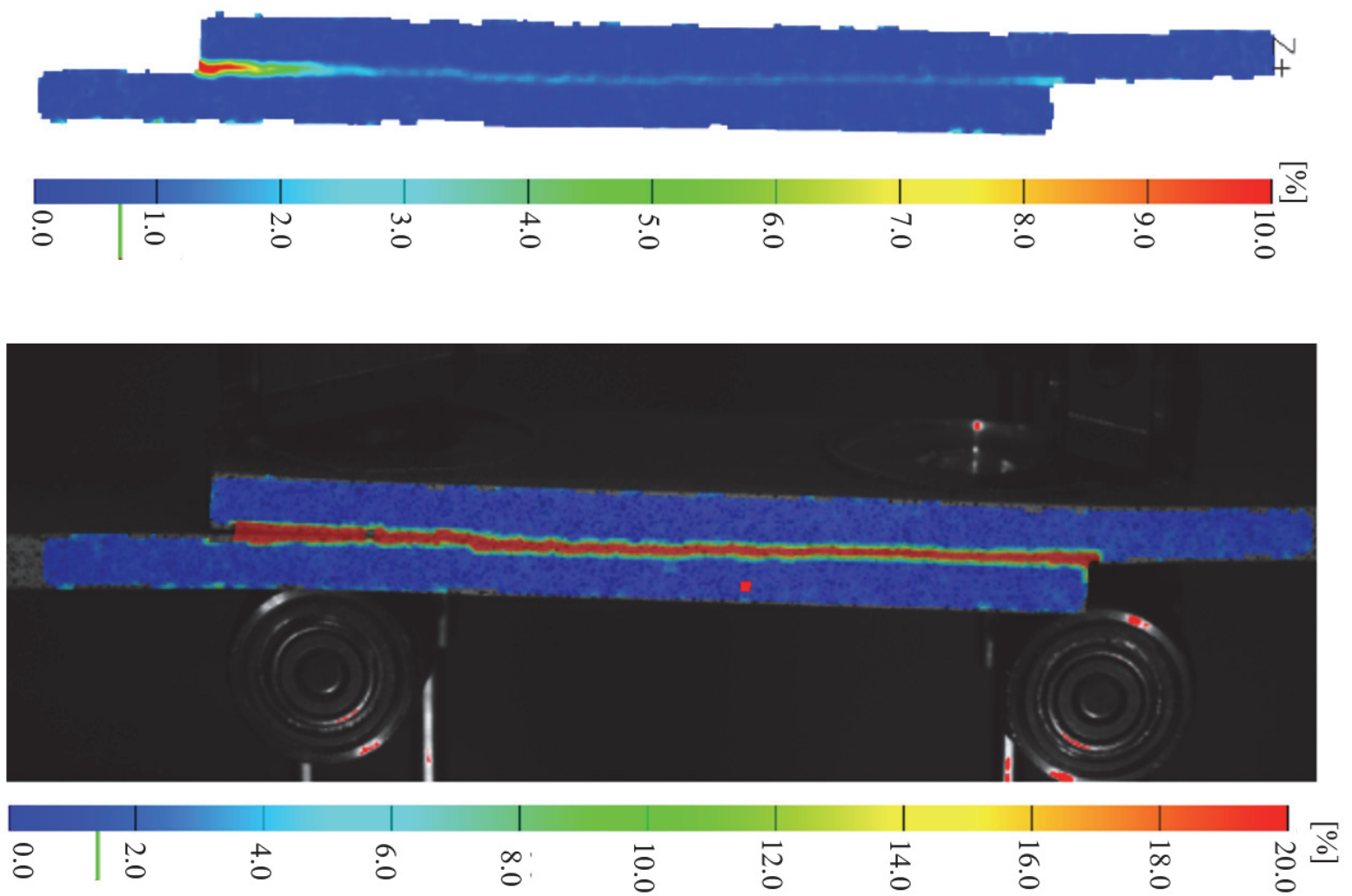

Figure 9: Local strains on the surface of a welded specimen at: a) middle load stage; b) maximum load stage.

Comparing the performance of both joints it can be verified that no significant differences occur in the strength values, which can be justified by the small hook size, which is a natural fracture trigger, reducing the strength [36]. Although both joint series collapse at similar maximum loads, the adhesive bonded joints show lower displacement at fracture.

\section{CONCLUSIONS}

Comparing the two types of joints, it is possible to draw the following conclusions:

- No significant differences in terms of strength between adhesive bonded joints and welded joints were found;

- Welded joints show elongation at break slightly higher than adhesive bonded joints;

- Adhesive boded process does not introduce any structural and mechanical change in the adherends, unlike the friction stir spot welding process;

- Adhesive bonded joints require curing time unlike welded connections that can be used immediately. 


\section{ACKNOWLEDGEMENTS}

$\mathrm{T}$

his research is sponsored by FEDER funds through the program COMPETE - Programa Operacional Factores de Competitividade - and by national funds through FCT - Fundação para a Ciência e a Tecnologia -, under the project UID/EMS/00285/2020.

\section{REFERENCES}

[1] Threadgill, P. L., Leonard, A. J., Shercliff, H. R. and Withers, P. J. (2009). Friction stir welding of aluminium alloys, Int. Mater. Rev., 54(2), pp. 49-93, DOI: 10.1179/174328009X411136.

[2] Mishra, R. S. and Ma, Z. Y. (2005). Friction stir welding and processing, Mater. Sci. Eng. R: Rep., 50(1-2), pp. 1-78, DOI: 10.1016/j.mser.2005.07.001.

[3] Braga, D. F., de Sousa, L. M. C., Infante, V., da Silva, L. F. and Moreira, P. M. G. P. (2016). Aluminium Friction-stir Weld-bonded Joints, J. Adhes., 92 (7-9), pp. 665-678, DOI: 10.1080/00218464.2015.1085860.

[4] Christner, B., McCoury, J. and S. Higgins: Proc. $4^{\text {th }}$ Int. Symp. On 'Friction stir welding', Park City, UT, USA, May 2003, TWI

[5] Banea, M. D., da Silva, L. F. M., Campilho, R. D. S. G. and Jesus, A. M. P. (2013). Characterization of Aluminium Single-Lap Joints for High Temperature Applications, Mater. Sci. Forum, 730-732; pp. 721-726, DOI: 10.4028/www.scientific.net/MSF.730-732.721

[6] Reis, P. N. B., Ferreira, J. A. M., Pereira, A. M. and Antunes, F. J. V. (2014). Influence of Superposition Length on Transverse Impact Response of Single-Strap Adhesive Joints, J. Adhes., 90(1), pp. 65-79, DOI: $10.1080 / 00218464.2013 .797341$

[7] Reis, P. N. B., Antunes, F. J. V. and Ferreira, J. A. M. (2005). Influence of superposition length on mechanical resistance of single-lap adhesive joints, Compos. Struct., 67(1), pp. 125-133, DOI: 10.1016/j.compstruct.2004.01.018.

[8] Sancaktar, E. and Nirantar, P. (2003). Increasing strength of single lap joints of metal adherends by taper minimization, J. Adhes. Sci. Technol., 17(5), pp. 655-675, DOI: 10.1163/156856103321340796.

[9] Vinson, J.R. (1989). Adhesive Bonding of Polymer Composites, Polym. Eng. Sci. 29(19), pp. 1325-1331, DOI: $10.1002 /$ pen.760291904.

[10] da Silva, L. F. M., Carbas, R. J. C., Critchlow, G. W., Figueiredo, M. A. V. and Brownc, K. (2009). Effect of material, geometry, surface treatment and environment on the shear strength of single lap joints, Int. J. Adhes. Adhes., 29(6), pp. 621-632, DOI: 10.1016/j.ijadhadh.2009.02.012.

[11] Lees, W.A. (1978). Stress distribution in-bonded joints: an exploration within a mathematical model, Int. J. Mater. Prod. Tecnol. 2, pp. 168-181, DOI: 10.1016/0261-3069(85)90054-8.

[12] Czarnocki, P. and Piekarski, K. (1986). Non-linear numerical stress analysis of a symmetric adhesive-bonded lap joint, Int. J. Adhes. Adhes. 6, pp. 157-160, DOI: 10.1016/0143-7496(86)90020-5.

[13] Sawa, T., Liu, J., Nakano, K. and Tanaka, J. (2000). A two-dimensional stress analysis of single-lap adhesive joints of dissimilar adherends subjected to tensile loads, J. Adhes. Sci. Technol., 14(1), pp. 43-66, DOI: $10.1163 / 156856100742104$

[14] Liu, J., Sawa, T. and Toratani, H. (1999). A Two-dimensional Stress Analysis and Strength of Single-lap Adhesive Joints of Dissimilar Adherends Subjected to External Bending Moments, J. Adhes. 69(3-4), pp. 263-291, DOI: $10.1080 / 00218469908017231$.

[15] da Silva, L. F. M., Critchlow, G. W. and Figueiredo, M. A. V. (2008). Parametric Study of Adhesively Bonded Single Lap Joints by the Taguchi Method, J. Adhesion Sci. Technol. 22(13), pp. 1477-1494, DOI: $10.1163 / 156856108 X 309585$.

[16] Hattori, T. (1991). A stress-singularity-parameter approach for evaluating the adhesive strength of single-lap joints, JSME Int. J. A-Sol. M. 34(3), pp. 326-331. DOI: 10.1299/jsmea1988.34.3_326.

[17] Czarnocki, P. and Piekarski, K. (1986). Fracture strength of an adhesive-bonded joint, Int. J. Adhes. Adhes. 6(2), pp. 93-95, DOI: 10.1016/0143-7496(86)90055-2.

[18] Mazumdar, S. K. and Mallick, P. K. (1998). Static and fatigue behavior of adhesive joints in SMC-SMC composites, Polym. Compos., 19(2), pp. 139-146, DOI: 10.1002/pc.10084.

[19] Groth, H. L. (1988). Stress singularities and fracture at interface corners in bonded joints, Int. J. Adhes. Adhes., 8(2), pp. 107-113, DOI: 10.1016/0143-7496(88)90031-0. 
[20] Papini, M., Fernlund, G. and Spelt, J. K. (1994). The effect of geometry on the fracture of adhesive joints, Int. J. Adhes. Adhes., 14(1), pp. 5-13, DOI: 10.1016/0143-7496(94)90015-9.

[21] Lang, T. P. and Mallick, P. K. (1998). Effect of spew geometry on stresses in single lap adhesive joints, Int. J. Adhes. Adhes., 18(3), pp. 167-177, DOI: 10.1016/S0143-7496(97)00056-0.

[22] Amijima, S. and Fujii, T. (1989). A simple stress analysis method for adhesive bonded tapered joints, Int. J. Adhes. Adhes., 9(3), pp. 155-160, DOI:10.1016/0143-7496(89)90111-5.

[23] Groth, H. L. and Nordlund, P. (1991). Shape optimization of bonded joints, Int. J. Adhes. Adhes., 11(4), pp. 204-212, DOI: 10.1016/0143-7496(91)90002-Y.

[24] Hildebrand, M. (1994). Non-linear analysis and optimization of adhesively bonded single lap joints between fibrereinforced plastics and metals, Int. J. Adhes. Adhes., 14(4), pp. 261-267, DOI: 10.1016/0143-7496(94)90039-6.

[25] Adams, R. D. and Harris; J. A. (1987). The influence of local geometry on the strength of adhesive joints, Int. J. Adhes. Adhes., 7(2), pp. 69-80, DOI: 10.1016/0143-7496(87)90092-3.

[26] Wang, C. H. and Rose, L. R. F. (2000). Compact solutions for the corner singularity in bonded lap joints, Int. J. Adhes. Adhes., 20(2), pp. 145-154, DOI: 10.1016/S0143-7496(99)00032-9.

[27] Kimiaeifar, A., Lund, E., Thomsen, O. T. and Sørensen, J. D. (2013). Asymptotic Sampling for reliability analysis of adhesive bonded stepped lap composite joints, Engineering Structures, 49, pp. 655-663.

[28] Kim, J. H., Park, B. J. and Han, Y. W. (2004). Evaluation of fatigue characteristics for adhesively-bonded composite stepped lap joint, Compos. Struct., 66(1-4), pp. 69-75, DOI: 10.1016/j.compstruct.2004.04.023.

[29] https://www.gleal.pt/files/products/145.pdf.

[30] https://www.gleal.pt/pt/produtos/5083.

[31] Pereira, A. M., Reis, P. N. B., Ferreira, J. A. M. and Antunes, F. V. (2013). Effect of saline environment on mechanical properties of adhesive joints, Int. J. Adhes. Adhes., 47, pp. 99-104. DOI: 10.1016/j.ijadhadh.2013.08.002.

[32] Hirulkar, N. S., Jaiswal, P. R., Reis, P. N. B. and Ferreira, J. A. M. (2020). Effect of hygrothermal aging and cyclic thermal shocks on the mechanical performance of single-lap adhesive joints. Int. J. Adhes. Adhes. 99, 102584, DOI: $10.1016 /$ j.ijadhadh.2020.102584.

[33] Hirulkar, N. S., Jaiswal, P. R., Reis, P. N. B. and Ferreira, J. A. M. (2019). Bending strength of single-lap adhesive joints under hygrothermal aging combined with cyclic thermal shocks, J. Adhes., DOI: 10.1080/00218464.2019.1681981.

[34] Leitão, C., Costa, M. I., Khanijomdi, K. and Rodrigues, D. M (2013). Assessing strength and local plastic behaviour of welds by shear testing, Mater. Des., 51, pp. 968-974, DOI: 10.1016/j.matdes.2013.04.100.

[35] Sun, Y. F., Fujii, H., Takaki, N. and Okitsu, Y. (2012). Microstructure and mechanical properties of mild steel joints prepared by a flat friction stir spot welding technique, Mater. Des., 37, pp. 384-392, DOI: 10.1016/j.matdes.2012.01.027.

[36] Lertora, E., Mandolfino, C., Pizzorni, M. and Gambaro, C. (2019). Influence of Adhesive in FSW: Investigation on Fatigue Behavior of Welded, Weld-Bonded, and Adhesive-Bonded Joints in Aluminum AA 6082 T6, Materials, 12, pp. 1-12, DOI: $10.3390 / \mathrm{ma} 12081242$.

[37] Tronci, A., Mckenzie, R., Leal, R. M. and Rodrigues, D. M. (2011). Microstructural and mechanical characterisation of 5XXX-H111 friction stir welded tailored blanks, Sci. Technol. Weld Joi. 16(5), pp. 433-439, DOI: $10.1179 / 1362171811 Y .0000000012$.

[38] Rodriguez, R. I., Jordon, J. B., Allison, P. G., Rushing, T. and Garcia, L. (2016). Low-cycle fatigue of dissimilar friction stir welded aluminum alloys, Mater. Sci. Eng. A, 654, pp. 236-248, DOI: 10.1016/j.msea.2015.11.075.

[39] Heydari, F., Amadeh, A. A., Ojo, O. O., Hasanniya, M. H. and Tamizifar, M. (2019). Microstructure and mechanical properties of autobody steel joined by friction stir spot welding, Sādhanā, 44(3), pp. 1-10, DOI: 10.1007/s12046-019-1057-5.

[40] Yang, X. W., Fu, T. and Li, W. Y. (2014). Friction Stir Spot Welding: A Review on Joint Macro and Microstructure, Property, and Process Modelling, Adv. Mater. Sci. Eng., 2014, 697170, DOI: 10.1155/2014/697170.

[41] Maciel, R., Infante, V., Braga, D., Moreira, P., Bento, T. and da Silva, L. (2019). Development of hybrid friction stir welding and adhesive bonding single lap joints in aluminium alloys, Frat. ed Integrità Strutt., 13(48), pp. 269-285. DOI: 10.3221/IGF-ESIS.48.28.

[42] Das, M., Madenci, E., and Ambur, D. R. (2008). Three-dimensional nonlinear analyses of scarf repair in composite laminates and sandwich panels. J. Mech. Mater. Struct., 3(9), 1641-1658, DOI: 10.2140/jomms.2008.3.1641. 